\section{Linear measurements for weight prediction in broodmares of three breeds}

Géraldine Blanchard', Jean-Paul Valette², Céline Robert², Jean-Marie Denoix ${ }^{2}$ and Bernard-Marie Paragon?

Nutrition Unit ${ }^{l}$ and UMR INRA Biomécanique et Pathologie Locomotrice du Cheval $^{2}$, Ecole Nationale Vétérinaire d'Alfort, Maisons-Alfort Cedex, France

\section{Introduction}

The prediction of body weight by body measurements is something useful in practice, for nutritionists, breeders and veterinerians as well. To date, the only published estimation of the body weight of breeding mares in France, based on body measurements is those of Martin-Rosset (1990), with no breed specified.

\section{Material and Methods}

An epidemiologic, longitudinal study was conducted in Normandy between 2002 and 2004 to identify risk factors in the etiopathogeny of developmental orthopaedic disease in the foal. A total of 143 broodmares of 3 breeds were followed for nutrition and their body weight recorded. In 2004, the height of the withers $(H)$, Girth's circumference $(G)$ and body weight (BW) measured on a scale, were available in the 2 months before weaning for 118 mares, aged 3 to 21 years old, with the following distribution by breed: 46 Thoroughbred from 5 stud farms, 49 French Trotter (Standardbred) from 4 stud farms and 23 Selle Français from 3 stud farms. Equations predicting BW were established, by breed, by multiple linear regression from $\mathrm{G}$ and $\mathrm{H}$.

The variables of $95 \%$ tolerance intervals for $90 \%$ of the population were used for the validation. The validity of the model was verified by a Student T-test. Equations predicting body weight were considered accurate if the regression between predicted weight and scale weight had a slope and an intercept not significantly different from 1 and 0 respectively. Accuracy was further evaluated by the percent error defined as (scale weight - predicted weight)/scale weight*100). Precision of the equations was assessed by $R^{2}$ and standard error of the estimate (SEE) defined as $\sqrt{ }[$ (scale weight - predicted weight) $\left.\mathrm{Hi}^{2} /(\mathrm{n}-2)\right]$. The body weight was also estimated using the equations of Martin-Rosset, and compared to the scale weight by the same analysis.

\section{Results}

The mean age of the broodmare is $9.55 \pm 3.9$ years. The distribution of the age of the broodmares at foaling is presented in Figure 1.
The predictive equations of the body weight are presented in the Table I.

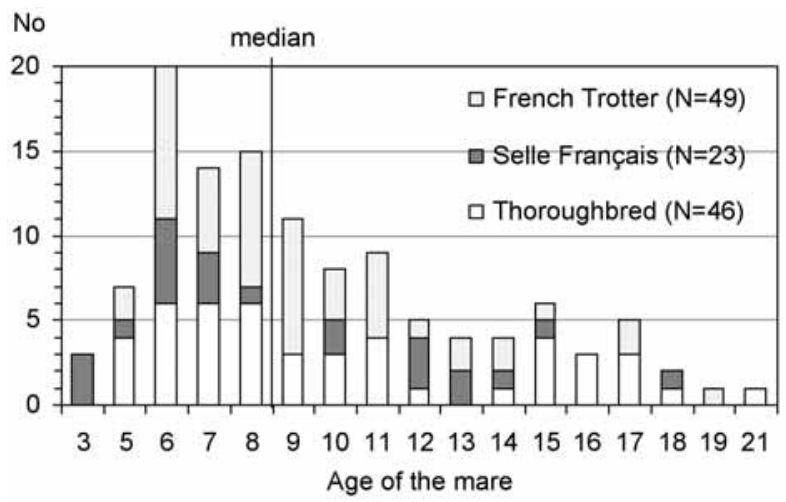

Fig 1 Distribution of the age of the broodmares at foaling, by breed.

Table I Predictive equations and standard error of the estimate (SEE) of the body weight (BW) of the mare, expressed in $\mathrm{kg}$, from height of the withers $(H)$ and Girth's circumference $(G)$ expressed in $\mathrm{cm}$.

\begin{tabular}{|l|l|c|}
\hline Breed & Equation & \multirow{2}{*}{ SEE } \\
\cline { 1 - 2 } Thoroughbred & BW $=2.30 \mathrm{H}+3.19 \mathrm{G}-428$ & \multirow{2}{*}{$29 \mathrm{~kg}$} \\
\hline French Trotter & $\mathrm{BW}=4.42 \mathrm{H}+3.76 \mathrm{G}-849$ & \\
\cline { 1 - 2 } Selle Français & $\mathrm{BW}=0.64 \mathrm{H}+5.78 \mathrm{G}-633$ & \\
\cline { 1 - 2 } Martin Rosset (1990) & $\mathrm{BW}=2.6 \mathrm{H}+5.2 \mathrm{G}-855$ & \multirow{2}{*}{$30 \mathrm{~kg}$} \\
\hline
\end{tabular}

Accuracy of the equations by breed was close to accuracy with Martin-Rosset's equation, with a slope not significantly different from 1 in the line of identity plots for both models (Figures 2 and 3). The y-intercept, not significantly different from 0 , seems better with the equations by breed compare to Martin-Rosset's equation (-4.2 kg versus $+55 \mathrm{~kg})$, as well as the precision ( $R^{2}$ of 0.69 versus 0.62 ) with a SEE comparable between both methods (29 kg vs $30 \mathrm{~kg}$ ) (Table I).

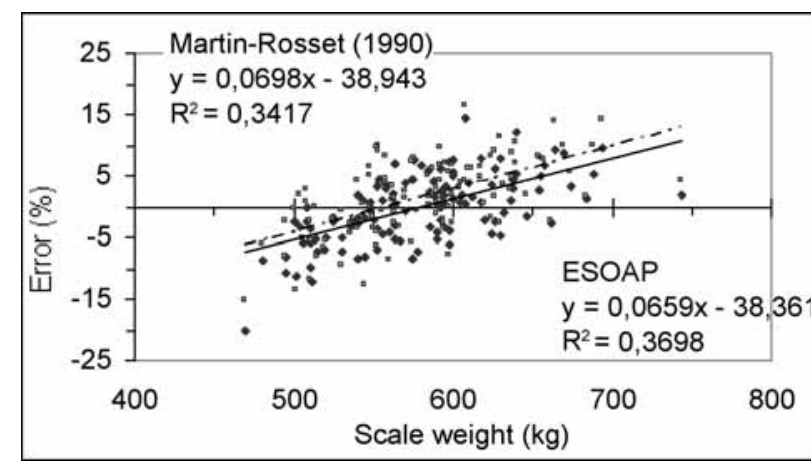

Fig 2 Percent error of the predicted weight versus scale weight at different scale weight, for the predictive equations by breed (ESOAP) and for the predictive equation of Martin-Rosset (1990).

\section{Discussion}

Unless still statistically valuable with our data, the standard error observed here applying Martin-Rosset's equation is different from the standard error initially announced by MartinRosset, i.e. $23 \mathrm{~kg}$, obtained with older data. This difference might be due to the diversity of the sample, as we have mares from three different breeds, weighting from 470 to $744 \mathrm{~kg}$. This large range of values, and the fact that we used the body measurements independently of the body condition score of 
the mares (ranging from 2.5 to 4, data not shown) can explain these results. Indeed, we were looking for a practical tool to estimate the body weight of the mares, and not an equation fitting only with mares in ideal body condition. We can not exclude a change in the morphology of the mares in the last decade or so, but this does not appear as a high probable explanation, as we find the same SEE with our equations.
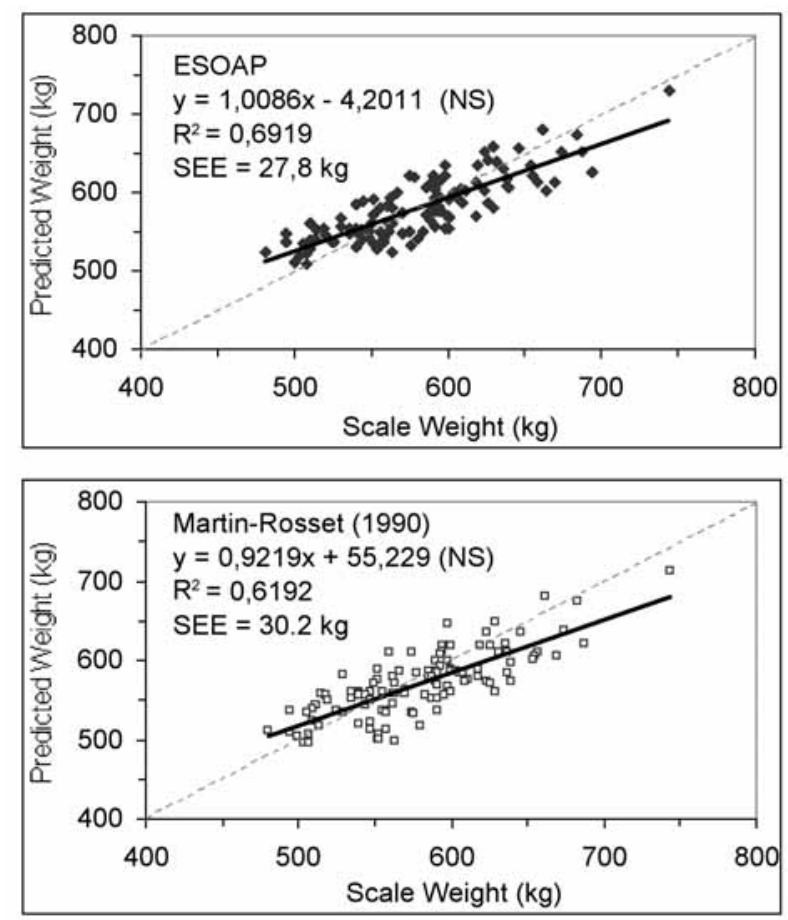

Fig 3 Regression of predicted weights against scale weights, with our predictive equations by breed (ESOAP), and with those of Martin-Rosset (1990). Dotted line is line of identity and solid line is the regression line fitting the data, with regression, $\mathrm{R}^{2}$ and standard error of the estimate (SEE) listed.

The equations by breed suggest a different impact of Height and Girth's circumference on the Body Weight of the mare among the three breeds, especially in Selle Français where the impact of the Height appears much lower than in the two other breeds. Analysed by breed, the best accuracy of the equations is the obtained for the Selle Francais (data not shown), unless they are the smallest group studied $(N=23)$ and the widest range of scale body weight (from $508 \mathrm{~kg}$ to $744 \mathrm{~kg})$.
The age of the mares does not seem to explain the disparity of the data as indeed only three mares, all Selle Francais, were only 3 years old when all the others were 5 years old and more as shown in Figure 1.

The timing to measure the mare also has to be discussed. The aim of the breeder is to obtain a foal per mare per year. So, theoretically, a broodmare is never at a maintenance state. An estimation of the body weight of the mare by body measurements is a useful tool for the breeder, the veterinarian and the nutritionist, as the measures can be obtained even in a field, far away form any scale. As we consider the maintenance weight to feed the mare, we had to look for a time to measure when the body weight of the mare could be the closest to her maintenance weight. Just after birth was not accurate, neither after weaning if she is pregnant again, as the foetus is already more than 5 months old (Martin-Rosset 1990). The best time to measure the mare is probably somewhere between the birth and the weaning. As we could not follow the mares month after month, as a first approach, we choose to take the measure in the two months before weaning, when we had to visit the farms for an other part of the study. This point could be enhanced by a follow up of the mares months after months during all the pregnancy.

In conclusion, this first predictive equations of the body weight of the mares, by breed, confirm the equation of Martin-Rosset (1990). But the size of the sample are still small, and these results should be confirmed by a study along the gestation, taking into account the body condition score of the mare, and the state of pregnancy.

\section{References}

Martin-Rosset W. (1990): L'alimentation des chevaux. Ed. INRA, Paris (France), 232

G. Blanchard

Nutrition Unit

Ecole Nationale Vétérinaire d'Alfort

94704 Maisons-Alfort Cedex

France

gblanchard@vet-alfort.fr 